\title{
A ARTE DA INDIA NO BRASIL
}

\author{
Carlos Alberto da Fonseca
}

A experiência artística da India começou a ser mostrada no Brasil com alguma insistência, divulgação mais maciça, amplitude e planejamento apenas na década atual. Seu conhecimento se deu nos anos 60, veiculado por alguns trabalhos do beatle George Harrison (1) e os anos de peregrinação de todo o conjunto pela postura filosófica indiana e a crescente popularidade que o guru espiritual dos rapazes adquiriu no Ocidente. Os Estados Unidos logo conheceram Ravi Shankar (2) nos concertos de Nova York: os discos gravados ao vivo alcançaram grande popularidade, favorecida pela atitude da love and peace generation.

Com o intuito de promover as visitas (três ao todo, até agora) de Ravi Shankar ao Brasil, seus discos começaram a ser prensados aqui. Oito deles podem ser encontrados com certa regularidade. Em Ravi Shankar, In concert e Portrait of a genius, RS se apresenta com sua sitar e um pequeno grupo que inclui tabla e tambura; o lado A de Ravi Shankar's family \& friends apresenta a cantora Lakshmi Shankar, e o lado B uma "Music for a ballet", de autoria de RS; Ravi Shankar's music festival from India reúne 17 músicos (28 instrumentos diferentes) e cantores; nos dois discos West meets East, Ravi Shankar interpreta algumas raga acompanhado pelo violino de Yehudi Menuhin (que, acompanhado pelo piano de Hephzibah Menuhin, interpreta sonatas romenas de Enesco no lado B); Ravi Shankar-André Previn apresenta um "Concerto for sitar and orchestra", de autoria do primeiro, acompanhado pela London Symphony Orchestra, regida pelo segundo)

(1) - "Tomorrow never knows" e "Love to you" (Revolver, 1966); "Within you withou you" (Sgt. Pepper's Lonely Hearts Club Band, 1967) e "The inner light" (1968). O acompanhamento com sitar já se fez presente em música brasileiras: "Balada do louco" (Mutantes, 1972, no LP Mutantes e seus cometas no país dos baurets, "Corsário" (Ney Matogrosso, seu último disco (show, 1975; de João Bosco e Aldir Blanc; tocada por Claudio Gobis).

(2) - Os nomes de pessoas e estados indianos estão grafados à inglesa, forma pela qual são difundidos no Ocidente. 
Com menos frequiência, alguns discos de música folclórica também podem ser encontrados. Nesse particular, os discos são todos importados, o que dificulta sobremaneira o conhecimento dessa vertente tradicional da música praticada na India. A Discoteca Pública Musical, de São Paulo, possui apenas dois discos:

a) Music of the Orient: a survey of the principal music of all high oriental cultures (número de chamada 8.37.1470): apresenta 5 peças de Bali, 1 de Sião ("Drama musical - cena da lenda de Rama") e 2 "canções artísticas" da India: "Raga Bhairavi" e "Raga Bilaval (?)";

b) Music from South Asia (número de chamada 9.49.1985A/B): apresenta peças do estado de Sorastra, vale de Kulu, Hyderabad, Goa, Nepal, Sind, Pathan, Paquistão, Caxemira e India Central - uma excelente mostra da diversidade da música tradicional indiana.

Nos dias 10, 11 e 12 de junho de 1976, comparecia ao palco do Teatro Galpão de São Paulo, o dançarino Astad Deboo, com o espetáculo Experimental Indian Dance, integrando o programa do "II Festival de Teatro" (3) Astad dançou alguns textos consagrados dos Purana e Mahabharata no vigoroso estilo kathakali. Em apresentação anterior, o Teatro Municipal de São Paulo (19 a 22 de novembro de 1975) já havia acolhido a dançarina Sonal Mansingh e sua companhia, com um programa levado também a Salvador, Rio de Janeiro, Brasília e Belo Horizonte. Acompanhada por Harekrishna (tabla), Nagarajan ( mrdaga), Sankaran (vina) e Radha Krishna (vocal - Sânscrito e Télugu), Sonal dançou doze peças em três estilos diferentes: seis bharatanatya (a mais antiga dentre as formas de dança clássica da India; a dança das devadasi, as dançarinas que bailavam nos templos e cortes da India em ocasiões especiais), quatro odissi (versão orissa do estilo anterior) e dois kuchipudi (essencialmente do povo, combina o clássico e o folclore e incorpora o espírito da çrngarabhakti "devoção erótica") $\mathrm{Na}$ semana seguinte à apresentação de Astad Deboo, o Teatro Municipal de São Paulo apresentou "Indrani e seus dançarinos e músicos da India" (16 a 19 de junho) O grupo, formado por Indrani, Krishna Venkatachalam e V P Ramakrishnan Nair (dançarinos), Visala Venkatachalam (vina e vocal) e Krishnan Shekharan (percussionista), apresentou-se, ainda, no Rio de Janeiro e Belo Horizonte, e domina os quatro estilos já referidos. A dançarina Krishna Venkatachalam (que se apresentava pela primeira vez

(3) - Além da India, compareceram outros grupos externos ao eixo Europa-América: Uganda (Renga Moi, em swahili, pela Abafumi Company); Irã (Caligula, de Albert Camus, em persa, pelos atores da Kargabe Nemayeshi); - grupo joponês Hamada Zenya Gekijo, que apresentaria $A$ and $B, m y$ colligate e Dai-shikko, não recebeu o visto de entrada no Brasil. 
fora da India) e o dançarino $V \quad P$ Ramakrishnan Nair dançam apenas kathakali: ela apresentou dois solos, ele um, e dançaram juntos um outro número; Indrani se encarregou dos outros três estilos: dois números bharatanatya, dois kuchipudi e um odissi .

Estes quatro estilo são originários de áreas diferentes do sul da India, e cada um conserva sua característica. O bharatanatya é cultivado no estado de Madras: só é apresentado em danças-solo por dançarinas. No kuchipudi, do estado de Andhra Pradesh, o solo é substituído por duas ou mais dançarinas; pode ser o suporte de uma dançasolo, caso em que se caracteriza como uma "dança-pura" (os gestos não são simbólicos, a música tem padrão rítmico livre e não há uma estória a ser contada) O odissi, do estado de Orissa, incorpora um número muito grande de variações gestuais que o bharatanatya se proíbe por ser a mais soberba e sóbria das formas de dança clássica; próprios para dançarinas, ambos são ainda apresentados em templos hindus. O kathakali, do estado de Kerala, é a "dança-drama" (conta uma estória) onde se pode perceber uma modificação mais profunda: aos poucos deixa de ser cultivado apenas pelos dançarinos e se incorpora ao repertório das dançarinas.

Essa nova disposição do estilo kathakali pôde ser constatada. Astad Deboo dança apenas kathakali, conservando-lhe a tônica de um vigoroso estilo masculino. Astad dançou a estória de Çakuntala e Dusyanta (relato que inicia o Mahabharata), onde se encarregou de caracterizar cinco personagens diferentes: o príncipe Dusyanta, seu cocheiro, a gazela perseguida e morta pelo príncipe, a bela Çakuntala e Kanva, o eremita que era seu pai adotivo. Dançando um espisódio cotidiano de Krsna adulto, Astad tornou visível o nascimento, a infância e a adolescência do deus: esses estágios foram mostrados em flashbacks, vividos pela mãe de Krsna enquanto ela lhe preparava uma refeição. Quase impossível contar as personagens: são fundamentalmente duas - mas se desdobram seguidamente: a mãe preparando a comida (presente) e Krsna adulto, no bosque, em diálogo galante com as gopi "pastoras" (presente): essas duas situações cruzam repetidamente o espaço da lembrança que se instala na mãe, que rememora, em certo instante, o $\mathrm{Krsna} /$ menino-travesso que rouba o mel guardado num pote colocado sobre um móvel bastante alto. $\mathrm{O}$ que faz Astad é transformar-se em cena em cortes rápidos: é, quase ao mesmo tempo, a mãe-que-cozinha, o menino-travesso, a mãe-quevigia-o-menino-travesso (parada à soleira de uma porta, vê o meninotravesso na cozinha e o adulto-galanteador no bosque), as gopi-dançando-e-conversando-com-Krsna. Nos instantes seguintes verifica-se a mesma estrutura complexa na representação do relato: e Astad se vale de apenas um véu (necessário para cobrir seu torso nu ao repre- 
sentar a mãe e as gopi) e uma variação infinita de gestos proporcionados por todo o seu corpo.

O vigor do estilo kathakali pôde ser percebido, também na peça Vanavarnana "Um quadro da floresta", dançada por V P Ramakrishnan Nair, em que um rei presencia uma luta de morte entre animais: uma serpente ataca um elefante; enquanto este luta contra seu inimigo, um leão salta sobre sua cabeça; o elefante, sem forças, é derrotado; o rei continua seu passeio (o dançarino descreve, ainda, o vento, os pássaros e outros animais da floresta)

Como se pode verificar, um kathakalin compõe (compunha) todas as personagens do relato: homens, mulheres e animais, numa variedade e acumulação que assombram e exigem uma atenção máxima, pois um mínimo gesto pode ser a entrada de outra personagem. Não apenas nas referidas, mas também nas outras dançadas por Astad, verifica-se que os temas que mais se conformam ao estilo kathakali são aqueles em que o número de personagens é bastante elevado e/ou as figuras encenadas se comportam com selvageria. Desenvolvido por dançarino-e-dançarina - pelo menos nas peças vistas até agora o estilo perde seu vigor ou cria um outro, mais diluído. Krishna Venkatachlam apresentou um número de dança-pura no estilo kathakali: Sari, em que a própria vestimenta da dançarina era o tema, as possibilidades e o limite de seus gestos. Krishna apresentou, ainda, uma dança-drama neste estilo, que colocou no palco toda a graça feminina: passeando num jardim, uma jovem vê um homem muito atraente; seu temperamento romântico explode e ela chega a identificar o estranho como deus do Amor e da Lua; conclui, finalmente, que se trata apenas de um homem belo. Krishna e Ramakrishnan Nair apresentaram uma dança-drama em que a incorporação do kathakali pelas dançarinas evidenciou um empobrecimento da tensão produzida no palco: a peça, se dançada por apenas uma pessoa, poderia ter apresentado um rendimento muito maior em termos de densidade dramática: "o demônio Lalita, em forma de bela mulher, entra no Paraíso e se encontra com Jayanta, por quem se apaixona. Tenta, por várias vezes, induzi-lo ao casamento; ele a rejeita e ela, furiosa, revela sua verdadeira identidade. Jayanta mata-a com sua espada" $\mathrm{Na}$ mais longa das peças apresentadas, e com um entrecho arrastado e repetitivo, o dançarino Ramakrishnan não repete sua performance conseguida com a peça Vanavarnana: obriga-se a permanecer quase imóvel enquanto Krisna/Lalita o assedia com longuíssimos elogios; os poucos instantes em que se desimobiliza acontecem nas "falas" de rejeição, na rápida cena de morte do demônio e, principalmente, nas cenas iniciais, em que mostra sua condição de filho do rei do Paraíso - cenas também desnecessariamente alongadas, pois todo o aparato 
das vestimentas (jóias, máscaras, cores vivas nas roupas bufantes, o enorme enfeite à cabeça, o andar majestoso e impostado) já seria suficiente, aliado a uma econômica sucessão de gestos, para caracterizá-lo. Astad Deboo, dançando o encontro do rei Yaçovarman com a terrivel deusa-demônio Kali, com um enredo em tudo semelhante ao anterior, valeu-se apenas de um colar e pulseiras (o disfarce de Kali) bela mulher) e de um fruto que, mastigado em cena e lançado para fora da boca, era o sangue que indicava a nova personagem, transformando o dançarino na $\mathrm{Kali} /$ demônio. A cena da morte enquadrou o inimaginável: Astad/príncipe Yaçovarman corta os seios de Astad/ demônio Kali, misturando, ainda, um grito de dor e uma gargalhada de vitória.

Além destas rápidas considerações sobre o estilo kathakali, a vinda destes artistas favoreceu uma outra verificação. Sonal e Indrani dançaram, no estilo kuchipudi, a peça Mandukaçabda (O relato sobre a rã) As apresentações das duas dançarinas possibilitaram uma comparação de duas performances de uma mesma peça, no mesmo estilo, por pessoas diferentes. Some-se o fato de Indrani ter sido orientadora de Sonal, e a capacidade mostrada por esta em se desvencilhar da orientação e, mesmo dentro das poucas possibilidades oferecidas pelo já consagrado, conseguir uma nova realização.

Quanto à compreensão pela platéia, a apresentação de Indrani foi mais feliz. A dança da India é uma linguagem que se elabora com o uso de todo o corpo: olhos, nariz, lábios, pescoço, braços, pernas, toxar, etc., além da complicadíssima linguagem das mãos e dedos, que se revela em gestos (mudra) cujos requintes, sugestões e sucessão rápida tornam, na maioria das vezes, quase imperceptíveis os detalhes da densa narração proposta no palco. Procurando corrigir uma ausência de informação quando da apresentação de Sonal Mansingh, a agenciadora dos concertos preparou para a visita de Indrani um programa ilustrado por algumas mudra: apenas quatro ("escrevendo uma carta", "abelha sobre um botão de lótus", "pássaro sobre um ramo" e "segurando uma flauta"), mas que podem abrir as portas de uma percepção mais aguda. Além disso, antes de cada apresentação, um locutor verbalizava o resumo da dança: o espectador sentia o impacto da síntese, captando-lhe os instantes fundamentais, para logo em seguida descobri-los, ampliados, no desenvolvimento da dança. Embora sem o resumo mínimo anterior, a apresentação de Astad Deboo foi pioneira na inovação (4)

(4) - A lamentar, nos programas distribuídos, a confusão feita com a grafia das palavras. Misturam-se formas das transliterações inglesa e francesa, além de se apresentar uma mesma palavra ora segundo uma transliteração que se aproxima de uma identificação com o sâncrito, ora é a forma próxima à de um falar moderno. Respectivamente, "veena" (vina), "moudra" (mudra), "bharata natya" e "bharat natya" (bharatanatya) 
A crítica paulistana recebeu acaloradamente as apresentações. "Para os espectadores ocidentais, talvez chegue a haver uma certa ingenuidade nas historinhas que os bailarinos ilustram com o corpo, dedos e mãos para evocar diretamente a natureza, um pássaro, uma rã, um peixe. Nota-se também uma pureza espiritual de há muito perdida pelo Ocidente. Capazes de ainda se comover com o luar, por exemplo, os indianos procuram reproduzi-lo com uma cascata de movimentos descendentes do braço, que desejam sugerir os raios luminosos caindo sobre a tera" (5) Os espectadores têm aumentado, não obstante os preços (quase) exorbitantes cobrados pelos ingressos, o que obriga a uma lotação do anfiteatro e galerias do Teatro Municipal: invariavelmente, na segunda parte de cada apresentação, os espectdores têm sido convidados às poltronas da platéia: visto bem à frente dos olhos, o espetáculo agrada muito mais. Já está programada, ainda para 1976, a apresentação do casal Radha e Raja; para 1977 já está prevista uma apresentação do estilo kathak, do norte da India.

Como se vê, parece ter sido firmada uma aceitação da dança indiana. Isto não acontece com o teatro e o cinema: nunca foram apresentados no Brasil uma peça ou um filme indiano. O Sidarta (Siddhartha) que aqui foi visto é adaptado do romance do alemão Hermann Hesse, produzido e dirigido pelo norte-americano Conrad Rooks, com fotografias do sueco Zven Nykvist. No elenco figuram artistas do teatro e cinema da India: Shashi Kapoor (como Siddhartha), Simi Garewal (como Kamala), Remesh Sharma, Pincho Kapoor, Amrik Singh, Shanti Hiranand, Kunal Kapoor; também o vestuário foi desenhado por uma indiana (Bhanu); a música foi composta, dirigida e cantada por Hemanta Kumar. O filme teve seus pontos positivos e negativos apontados pela crítica. Mas ressalte-se a reconstituição do contexto social da India do século V a. C. e a oportunidade única da divulgação da atividade dos artistas de teatro e cinema indiano.

Também a pintura indiana foi divulgada entre nós. A exposição Pinturas contemporâneas da India foi organizada pela LalitKala Akadami, patrocinada pelo Ministério das Relações Exteriores da India no Brasil. A coleção de 54 obras, selecionadas entre os trabalhos de 17 pintores, foi exposta, em São Paulo, entre 7 e 30 de junho de 1971, na Fundação Armando Alvares Penteado (em agosto foi exposta no Rio de Janeiro e entre setembro e outubro em Salvador) A mostra deixou claro que "o artista contemporâneo da India basicamente compartilha do tremendo espírito de aventura e da liberdade de expressão artística com os semelhantes em todo o mundo e, também com isso, uma abordagem eclética dos problemas técnicos e um alto grau de

(5) - Revista VEJA, 23 de junho de 1976. 
individualismo que é, talvez, o dom mais significativo da era moderna. A sua simpatia por seu próprio patrimônio é indiscutível, porém a influência de sua rica tradição não vem à tona importunamente" A recriação do tradicional, em função de conceitos e práticas internacionais, foi a tônica da exposição.

Restrita ainda aos tradicionais centros de cultura brasileiros (São Paulo, Rio de Janeiro e Salvador com extensões a Belo Horizonte e Brasília), a arte da India parece estar conquistando, pouco a pouco, uma terreno sólido, e se fixando - pelo menos a dança - como um programa regular (7)

(6) - S. A. Krishnan, editor do catálogo da exposição.

(7) - Estas notas foram redigidas no final de 1976. Alguns fatos acontece-am depois dessa data: foi lançado mais um disco de Ravi Shankar (Transmigration - trilha sonora para um filme inglês); não veio o casal Radha e Raja e nem a apresentação do estilo Kathak - mas algumas academias brasileiras de dança já ensinam passos indianos; quanto ao teatro, há notícia de uma representação, no Rio de Janeiro, na década de 60 , de um texto de Rabindranath Tagore, traduzido por Cecília Meireles ( $O$ carteiro?) - mas faltam indicações mais precisas. 